\title{
INFLUENCE OF WATER EXTRACTION METHODS FROM ENVIRONMENTAL SAMPLES ON MEASURED TRITIUM LEVEL
}

\author{
Carmen Varlam*, Diana Bogdan, Irina Vagner, Diana Costinel \\ National Research and Development Institute for Cryogenic and Isotopic Technologies - ICSI \\ Ramnicu Valcea, 4 Uzinei Street, 240050 Ramnicu Valcea, Romania
}

\begin{abstract}
:
In order to validate the laboratory routine procedure of tritium activity concentration determination in tissue free water of environmental samples, parallel measurements were performed in water extracted from wild vegetation by two methods: azeotropic distillation and lyophilization (recommended by a French standard method). The sample humidity was established using the drying procedure to constant mass of the sample, and isotopic effect that may occur during lyophilization procedure was investigated by deuterium ratio determination in sample and extracted water. Traces of toluene in extracted water by azeotropic distillation made deuterium ration determination useless.
\end{abstract}

\section{Article info:}

Received 22 July 2021

Received in revised form 9

September 2021

Accepted 4 October 2021

Available online 9 November 2021

Keywords:

Tritium, deuterium, azeotropic

distillation, liophilization

How to cite: Varlam, C., Bogdan, D., Vagner, I., Costinel, D., (2021). Influence of Water Extracted Methods on Measured Tritium Level. Smart Energy and Sustainable Environment, 24(2), 89-96, https://doi.org/10.46390/j.smensuen.24221.441

\section{INTRODUCTION}

Tritium is produced both by a natural process, the interaction of cosmic rays with the atmosphere, and by anthropogenic processes (in nuclear reactions). More than 80 percent of tritium in the environment was released in the 1950s and early 1960s by above-ground nuclear weapons testing in many countries. Bomb-generated tritium decayed following physics laws, and was washed-out of the atmosphere by rain during the 1970s and 1980s. By 1990 to 1992, tritium in precipitation in North America had reached low levels that have since remained around 9 TU in Albuquerque (Eastoe et al., 2012). Same level (taking account of measurement uncertainties), around $10 \mathrm{TU}$, can be found in Central Europe (International Atomic Energy Agency, 2020). Tritium is also used in a variety of consumer products, such as illuminated watches, thermostat dials, and airplane exit lights. Both the natural and man-made sources have contributed to a world-wide "background" level of

*Corresponding author: Carmen Varlam, E-mail: Carmen.Varlam@icsi.ro, ORCID: 0000-0003$3325-822 X$ 
tritium, around 1-4 Bq/l of water extracted from environmental samples (Institute de Radioprotection et de Sureté Nucleaire, 2020).

The Experimental Pilot for Tritium and Deuterium Separation (PESTD) from heavy water is a research nuclear facility. One of the main task of Tritium Laboratory, part of PESTD, is to monitor tritium effects in the environment. There are two modes that PESTD releases can interact with the environment: by liquid effluents through sewage, and by gaseous effluents through atmospheric releases. By establishing environment tritium level in a complex monitoring program, can be demonstrated compliance with Romanian national regulations (National Commission for Nuclear Activity Control, 2000) for nuclear facility. As part of this program, PESTD collects hundreds of samples throughout the year and analyzes them for tritium activity concentrations. Samples are collected both in the surrounding PESTD communities and onsite (Varlam et al., 2017). Tritium measurement must be performed in a variety of samples as: air, rainwater, vegetation, soil, surface water, drinking water, river sediment, aquatic plants, fish, and food products from surrounding communities.

The aqueous form of sample is usually prepared for tritium measurement, whether it is a gaseous sample, liquid sample, or assimilated in living organisms as tissue free water tritium and organically bound tritium (United Nations Scientific Committee on the Effect of Atomic Radiation, 2016). The liquid scintillation method is preferred method for tritium activity concentration measurement in aqueous samples, this method being an ISO standard method (ISO 9698, 1998) since 1998, during this period undergoing different revisions, the last version being in 2019 (ISO 9698, 2019). In July 2016, l'Association Française de Normalisation (AFNOR) published a standard method (XP M 60-824, 2016) for tritium measurement in tissue free water of environmental samples and organically bound tritium. Recommended method of free water extraction from environmental samples is lyophilisation. This method has an important drawback, it is time consuming, this property being an essential disadvantage in a monitoring program where many food products are concentrated during the summer months.

The routine procedure applied in Tritium Laboratory for water separation from environmental samples uses azeotrope distillation (Varlam et al., 2011). Toluene was chosen as solvent of this procedure due to compatibility of aromatics hydrocarbons with the liquid scintillation cocktail used in the measurement process. Water's azeotropic distillation is common used in oil industry, and was applied in the early tritium monitoring program (Moghissi et al., 1973). Despite the fact that distillation under various temperature and pressures is one of the common water separation techniques from various type of samples, different biases of tritium concentration were reported (Le Goff et al., 2014). If the distillation procedure is not conducted to the final stage, biases may be introduced as a results of isotopic effect. These biases increase as the temperature decreases. If the distillation is conducted to complete dryness, sample decomposition may occur resulting chemiluminescent phenomenon and/or quenching in liquid scintillation counting. In order to investigate method influence on water extracted from environmental samples in the subsequent liquid scintillation counting, wild vegetation was prepared using lyophilisation and azeotrope distillation. The extracted water was measured using the laboratory routine procedure of tritium measurement and the results were compared. Deuterium measurements were also performed in samples and extracted water by the two methods in order to evaluate isotopic effect. 


\section{EXPERIMENTAL}

$2.5 \mathrm{~kg}$ of wild vegetation were collected from the Institute yard. The amount was chopped and homogenized being discarded roots and woody steams. It was split in seven aliquots of around $320 \mathrm{~g}$ each, sealed in bags and frozen. Simultaneous were prepared from the same bag $100 \mathrm{~g}$ of vegetation for azeotrope distillation, $100 \mathrm{~g}$ for dry in oven, $100 \mathrm{~g}$ for lyophilisation, and $20 \mathrm{~g}$ for deuterium measurement. The ratio sample/toluene was $1 / 3$, and azeotrope distillation was performed using a LABOROTA 4200 rotary evaporator system, fig.1.

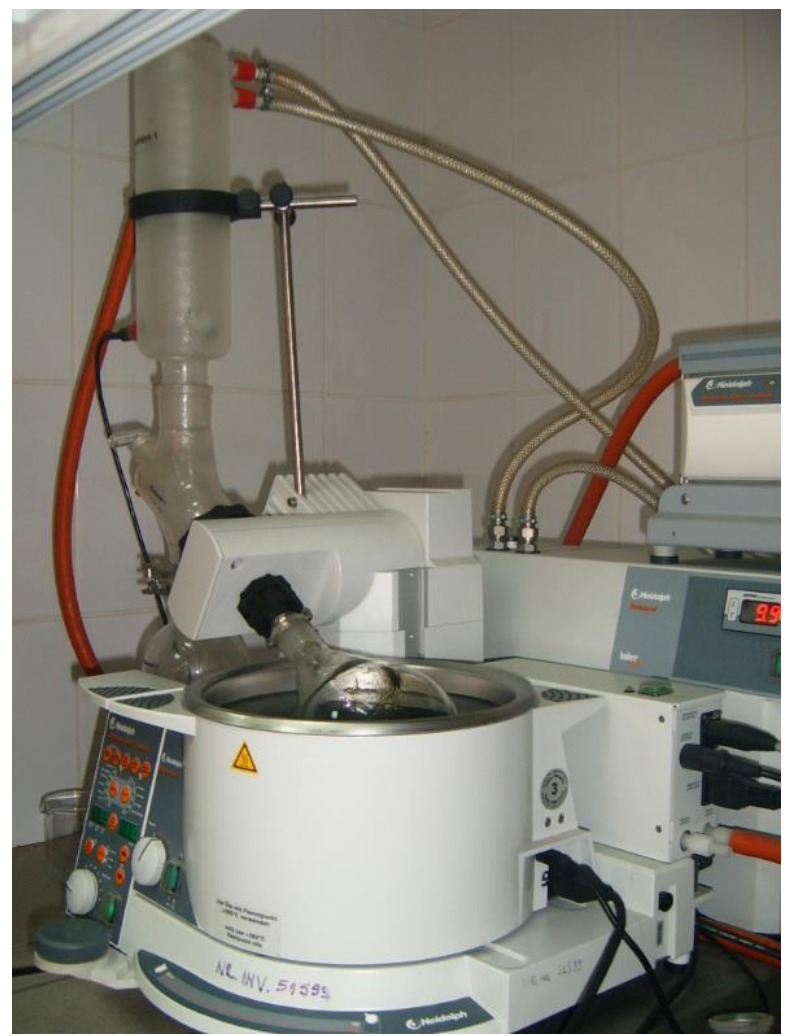

Figure 1. Azeotropic distillation using LABOROTA 4200 equipment

In order to establish the sample humidity, $100 \mathrm{~g}$ of wild vegetation were dried in the oven at $60^{\circ} \mathrm{C}$ until constant mass. The fresh and dried samples were weighted using a calibrated balance (OHAUS Explorer Pro EP413CM). The lyophilisation process was performed using a home-made lyophilisation installation. Samples were placed in $500 \mathrm{ml}$ flask, frozen with liquid nitrogen, and Tissue Free Water Tritium (TFWT) was cryogenically transferred under vacuum of 10-2mbar, fig. 2. Time consumed for this procedure was around 12 hours. 


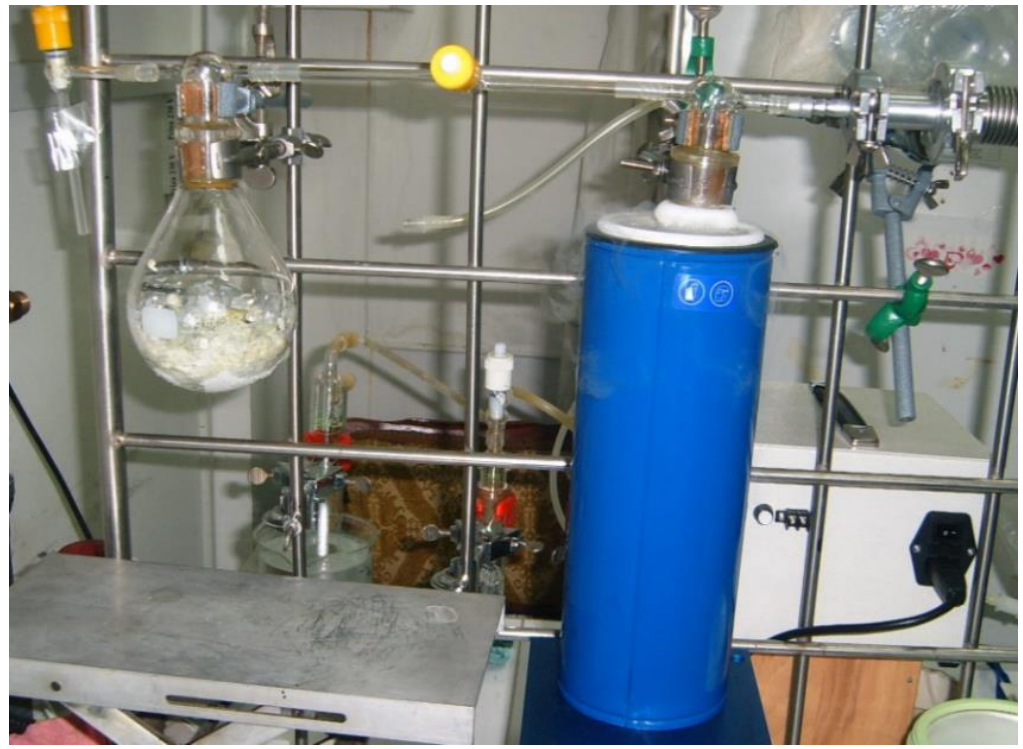

Figure 2. Home-made lyophilisation installation

The deuterium isotopic ratio was determined using the Gas Bench II device together with Continuous Flow Isotope Ratio Mass Spectrometer (CF-IRMS) Delta V Plus (Thermo Electron, Bremen-Germany). The Gas Bench II is a flexible continuous flow preparation device and inlet system with repetitive loop injection of gases. It is supported by a robotic auto sampler and using septum-sealed sample vials (Costinel et al., 2009). The ${ }^{2} \mathrm{H} /{ }^{1} \mathrm{H}$ ratio is measured and reported as $\delta^{2} \mathrm{H}$. The analytical uncertainty was $\pm 1 \%$. Laboratory standards (surface, ground and distilled waters at natural level) were used for $\delta^{2} \mathrm{H}$ analyses, periodically measured against international reference materials supplied by the International Atomic Energy Agency (IAEA) Vienna, the primary reference being V-SMOW (Vienna Standard Mean Ocean Water) and VSLAP (Vienna Standard Light Antarctic Precipitation) (Popescu et al., 2015).

TFWT was measured using the laboratory routine procedure that follows standard method recommendations. $8 \mathrm{~g}$ of purified water was mixed with $12 \mathrm{~g}$ of scintillation cocktail Ultima Gold uLLT (Perkin Elmer) in polyethylene vial of $20 \mathrm{ml}$. The background samples was prepared using Deuterium depleted water $(5 \mathrm{ppm} \mathrm{D} / \mathrm{D}+\mathrm{H})$. The liquid scintillation spectrometer was Quantulus 1220 (Perkin Elmer). The counting efficiency was evaluated by internal standard method (Varlam et al., 2009), using diluted Tritiated water provided by Perkin Elmer (certified activity of $2632100 \pm 3.208 \%$ disintegration per minutes/g, reference date June 2017). The samples and background were measured 10 cycles with 50 minutes counting time/cycle. During the measurement batch, the counting efficiency was $28.8 \%$, and the background was $0.847 \pm 0.04$ counts per minutes, at the best figure of merit. The detection limit according standard method was below $0.4 \mathrm{~Bq} / \mathrm{l}$. The reported uncertainty is calculated according tritium standard recommendations.

\section{RESULTS AND DISCUSSION}

Due to different species present in the wild vegetation sample, and expected different behavior during the lyophilisation process, first comparison is between 
humidity established by the two methods: drying in oven to the constant mass and lyophilisation, table 1 . The reported uncertainty is calculate taking account the repeated weighing of the sample.

Table 1. Sample humidity established by two methods: oven drying and lyophilisation

\begin{tabular}{|c|c|c|}
\hline Sample & Oven drying humidity[\%] & Lyophilisation humidity [\%] \\
\hline 1 & $81.1 \pm 2.5$ & $79.7 \pm 2.4$ \\
\hline 2 & $83.3 \pm 2.5$ & $81.2 \pm 2.4$ \\
\hline 3 & $80.3 \pm 2.5$ & $79.9 \pm 2.4$ \\
\hline 4 & $82.3 \pm 2.5$ & $80.8 \pm 2.4$ \\
\hline 5 & $82.5 \pm 2.5$ & $81.6 \pm 2.4$ \\
\hline 6 & $84.8 \pm 2.5$ & $84.8 \pm 2.5$ \\
\hline 7 & $83.4 \pm 2.5$ & $82.8 \pm 2.5$ \\
\hline Mean & $82.5 \pm 2.5$ & $81.5 \pm 2.4$ \\
\hline$\sigma^{*}$ & 1.49 & 1.78 \\
\hline
\end{tabular}

*reported standard deviation $\sigma$ was calculated using all 7 values of humidity, for the two methods used.

The reported means are the same for the two methods in the declared uncertainties. Observed standard deviation is lower than the reported uncertainty for each method. Less extracted water from the sample can be see for lyophilisation, e.g. sample 1, sample 3, and sample 4 (lower humidity). This can induce an isotopic effect. In order to identify this phenomenon deuterium ratio determinations were performed in frozen sample, in water extracted by lyophilisation, and in water extracted by azeotrope distillation, table 2 .

Table 2. Deuterium ratio for sample, water extracted by lyophilisation and azeotrope distillation

\begin{tabular}{|c|c|c|c|}
\hline Sample & $\begin{array}{c}\delta^{2} \mathrm{H} \text { of sample } \\
{[\% \text { o }}\end{array}$ & $\begin{array}{c}\delta^{2} \mathrm{H} \text { of lyophilized water } \\
{[\% \text { ] }}\end{array}$ & $\begin{array}{c}\delta^{2} \mathrm{H} \text { of azeotrope distilled water } \\
{[\% \text { ] }}\end{array}$ \\
\hline 1 & $-29.89 \pm 1.20$ & $-29.92 \pm 1.20$ & $-45.34 \pm 1.81$ \\
\hline 2 & $-30.17 \pm 1.21$ & $-34.42 \pm 1.38$ & $-49.21 \pm 1.97$ \\
\hline 3 & $-33.77 \pm 1.35$ & $-26.26 \pm 1.05$ & $-38.09 \pm 1.52$ \\
\hline 4 & $-35.03 \pm 1.40$ & $-35.05 \pm 1.40$ & $-53.67 \pm 2.15$ \\
\hline 5 & $-32.57 \pm 1.30$ & $-32.89 \pm 1.32$ & $-45.48 \pm 1.82$ \\
\hline 6 & $-34.63 \pm 1.39$ & $-33.78 \pm 1.35$ & $-49.75 \pm 1.99$ \\
\hline 7 & $-35.30 \pm 1.41$ & $-35.79 \pm 1.43$ & $-48.27 \pm 1.93$ \\
\hline Mean & $-33.05 \pm 1.32$ & $-32.59 \pm 1.30$ & $-47.12 \pm 1.88$ \\
\hline
\end{tabular}

The frozen samples had a mean of $-33.05 \pm 1.32 \%$ deuterium ratio varying between $-29.89 \pm 1.20 \%$ and $-35.30 \pm 1.41 \%$, values that can be explain by the presence in different proportion of different species and different growth stage. The extracted lyophilized water had a mean of $-32.59 \pm 1.30 \%$ deuterium ratio very close to that of frozen sample. Instead, its range of variation is wider between $-26.26 \pm 1.05 \%$ and $-35.79 \pm 1.43 \%$. The isotopic effect can be seen for sample 3 , due to les extracted water (its humidity is lower than established mean) heavy isotopes remain trapped in the sample and deuterium ratio of extracted water was enriched at $-26.26 \pm 1.05 \%$, comparing with the value of the same frozen sample, $-33.77 \pm$ $1.35 \%$. This behavior was observed for one sample only, all the other values being in the accepted uncertainties. Despite the special treatment of water extracted by azeotrope distillation (it was passed through active charcoal) the trace of toluene remained as a mark on deuterium ratio, the mean being $-47.12 \pm 1.88 \%$, much depleted than that of frozen samples and 
lyophilized samples. This measurement did not give any useful information on isotopic effect in azeotrope distillation.

Regarding tritium concentration of the samples, the extracted water by the two methods was measured applying the laboratory routine procedure for aqueous sample described above. Conversion to fresh sample was obtained using the humidity established by constant mass procedure. The results are presented in table 3 .

Table 3. Tritium activity concentration in wild vegetation obtained by azeotrope distillation and lyophilisation

\begin{tabular}{|c|c|c|}
\hline Sample & $\begin{array}{c}\text { Tritium activity concentration }- \\
\text { azeotrope distillation }[\mathrm{Bq} / \mathrm{kg} \mathrm{fw}]\end{array}$ & $\begin{array}{c}\text { Tritium activity concentration }- \\
\text { lyophilisation }[\mathrm{Bq} / \mathrm{kg} \mathrm{fw}]\end{array}$ \\
\hline 1 & $1.98 \pm 0.46$ & $1.86 \pm 0.45$ \\
\hline 2 & $1.65 \pm 0.47$ & $2.14 \pm 0.47$ \\
\hline 3 & $1.99 \pm 0.46$ & $1.43 \pm 0.44$ \\
\hline 4 & $1.92 \pm 0.47$ & $1.70 \pm 0.45$ \\
\hline 5 & $2.09 \pm 0.47$ & $1.67 \pm 0.46$ \\
\hline 6 & $1.64 \pm 0.47$ & $2.67 \pm 0.50$ \\
\hline 7 & $2.85 \pm 0.50$ & $1.61 \pm 0.46$ \\
\hline Mean & $2.02 \pm 0.47$ & $1.82 \pm 0.46$ \\
\hline$\sigma^{*}$ & 0.40 & 0.42 \\
\hline
\end{tabular}

*reported standard deviation $\sigma$ was calculated using all 7 values of tritium activity concentration obtained after applying the two mentioned methods

Tritium values for azeotrope distillation had a mean of $2.02 \pm 0.47 \mathrm{~Bq} / \mathrm{fw}$ with a range of variation between $1.64 \pm 0.47 \mathrm{~Bq} / \mathrm{fw}$ and $2.85 \pm 0.50 \mathrm{~Bq} / \mathrm{fw}$. The mean for lyophilisation was $1.82 \pm 0.46 \mathrm{~Bq} / \mathrm{fw}$, difference between the two means being $0.2 \mathrm{~Bq} / \mathrm{fw}$ smaller than the reported uncertainty. Its range of variation was similar to the azeotrope distillation, between $1.43 \pm 0.44 \mathrm{~Bq} / \mathrm{fw}$ and $2.67 \pm 0.50 \mathrm{~Bq} / \mathrm{fw}$. Standard deviation of the batch of seven samples was also lower than reported uncertainty, proven the capacity to obtain the valid results by both procedures. No isotopic effect was observed due to the statistical nature of radioactive decay, which attached a higher uncertainty to the measurement comparing to deuterium ratio determination.

\section{CONCLUSIONS}

The French standard method recommends lyophilisation for the extraction of water from environmental samples, method which is time consuming. In order to validate the laboratory routine procedure that uses azeotrope distillation, parallel measurements on wild vegetation were performed. Close results were obtained by the two investigated methods, difference being less than reported uncertainty. Isotopic effect was observed only to deuterium ratio determination, to one sample with water extracted by lyophilisation. The uncertainty attached due statistical nature of disintegration makes tritium measurement insensitive to isotopic effect, especially for environmental samples were level can be near or lower than the limit of detection of the liquid scintillation method.

Acknowledgements: The authors of this papers would like to acknowledge the technician working in Tritium Laboratory Elvis Udrea. 
Funding: This paper was prepared in connection with the work done for monitoring program of Experimental Pilot for Tritium and Deuterium Separation - PESTD.

Author Contributions: Carmen Varlam analyzed/interpreted the data and draft the manuscript with the help of Irina Vagner, Diana Bogdan prepared the samples by the two methods, Diana Costinel performed deuterium ratio determination.

Conflict of Interest Statement: There is no conflict of interest on this article.

\section{REFERENCES}

Costinel, D., Grecu, V., Vremera, R., Cuna, S., 2009, Stable oxigen and hidrogen isotopes measurement by CF-IRMS with application in hydrology studies, Journal of Physics, Conference Series 182012038 , https;//doi.org/10.1088/1742-6596/182/1/011002.

Eastoe, C.J., Watts, C.J., Ploughe, M., Wright, W.E., 2012, Future use of Tritium mapping pre-bomb groundwater volumes, Ground Water, 50 (1), 87-93, doi: 10.1111/j.1745-6584.2011.00806.x.

International Atomic Energy Agency, 2020, International Atomic Energy Agency/World Meteorological Organization IAEA/WMO, Global Network of Isotopes in Precipitation, "The GNIP Database"; http://www.iaea.org/water (current as of September 2020).

ISO 9698:1998, Water Quality - Determination of tritium activity concentration - Liquid scintillation counting method.

ISO 9698:2019, Water Quality - Tritium - Test method using liquid scintillation counting.

Institute de Radioprotection et de Surete Nucleaire, Radionuclide Fact Sheet Tritium and the Environment, https://www.irsn.fr/EN/Research/publications-documentation/radionuclides-sheets/environment/ Documents/Tritium_UK.pdf(current as of May 2020).

Le Goff, P., Duda, J.-M., Guetat, P., Rambaud, P., Mavon, C., Vichon, L., Badot, P.-M., Fromm, M., 2014, Measurement of tritium in the free water of milk: spotting and quantifying some biases and proposing ways of improvement, Journal of Environmental Radioactivity, 127, 1-10, http://dx.doi.org/10.1016/j.jenvrad.2013.09.006.

Moghissi, A.A., Brethauer, E.H., Compton, E.W., 1973, Separation of Water from Biological and Environmental Samples for Tritium Analysis, Analytical Chemistry, 45(8), 1565-1566, https://doi.org/10.1021/ac60330a066.

National Commission for Nuclear Activity Control, (2000), Fundamentals Norms on Radiological Safety, M.O. no. 404/29 august 2000, 22/124, in Romanian.

Popescu, R., Mimmo, T., Dinca, O.R., Capici, C., Costinel, D., Sandru, C., Ionete, R.I., Stefanescu, I., Axente, D., 2015, Using stable isotopes in tracing contaminant sources in an industrial area: A case study on the hydrological basin of the Olt River Romania, Science of the Total Environment, 533, 17 23, https://doi.org/10.1016/j.scitotenv.2015.06.078.

United Nations Scientific Committee on the Effect of Atomic Radiation - UNSCEAR, 2016, Report to the General Assembly, Scientific Annex C- Biological effects of the selected internal emitters - Tritium. Available at https://www.unscear.org/docs/publications/2016/UNSCEAR_2016_Annex-C.pdf, (current as of January 2020).

Varlam, C., Stefanescu, I., Duliu, O.G., Faurescu, I., Popescu, I., 2009, Applying direct liquid scintillation counting to low level tritium measurement, Applied Radiation and Isotopes, 67, 812-816, https://doi.org/10.1016/j.apradiso.2009.01.023.

Varlam, C., Stefanescu, I., Faurescu, I., Vagner, I., Faurescu, D., Bogdan, D., 2011, Establishing routine procedure for environmental tritium concentration at ICIT, Romanian Journal of Physics, 56 (1-2), 233-239. 
Varlam, C., Stefanescu, I., Faurescu, I., Bidica, N., Vagner, I., Faurescu, D. Bogdan, D., 2017, Tritium Level Evolution in the Environment at Experimental Pilot for Tritium and Deuterium Separation - ICSI, Fusion Science and Technology, 71:3, 339-343, http://dx.doi.org/10.1080/15361055.2017.1289451.

XP M 60-824, 2016, Énergie nucléaire - Mesure de la radioactivité dans l'environnement - Méthode d'essai pour l'analyse du tritium de l'eau libre et du tritium organiquement lié dans les matrices environnementales, published by l'Association Française de Normalisation (AFNOR) in French.

This article is an open access article distributed under the terms and conditions of the Creative Commons Attribution (CC BY-NC-ND 4.0) license (https://creativecommons.org/licenses/by-nc-nd/4.0/). 